\title{
Vaginal palpation versus transabdominal ultrasound in the comprehension of pelvic floor muscle contraction after vaginal delivery: a randomised controlled trial
}

\author{
Mayumi Ikeda ${ }^{1 *}$ (D) and Akiko Mori
}

\begin{abstract}
Background: Pelvic floor muscles support the pelvic organs and control voiding. The first choice in the repair of pelvic floor function that is damaged during pregnancy and delivery is pelvic floor muscle training, which involves repeated muscle relaxation and contraction. However, as muscle contractions cannot be visualised, it is difficult to assess whether patients understand how to contract them. Therefore, we assessed patients' comprehension of pelvic floor muscle contraction by comparing two teaching methods, vaginal palpation and transabdominal ultrasound, following vaginal delivery. We hypothesised that vaginal palpation is better than transabdominal ultrasound in this regard.
\end{abstract}

Methods: This randomised controlled trial conducted in facilities in Tokyo, Japan between July 2018 and January 2019 included women aged $\geq 20$ years at 4-6 weeks after vaginal delivery. The randomisation involved website-based centralised allocation. The primary outcome was a change in bladder base displacement during pelvic floor muscle contraction before and after training, which was measured using transabdominal ultrasound. Participants performed three contractions for $3 \mathrm{~s}$, and the mean value was used for statistical analysis. The secondary outcome was a change in understanding the contraction before and after training, which was measured using a five-point Likert scale questionnaire. Outcomes were analysed using Welch's t-test.

Results: Sixty-five participants were randomly allocated to the vaginal palpation group $(n=32)$ and transabdominal ultrasound group $(n=33)$. Baseline characteristics were similar between the groups. Changes in bladder base displacement were not significantly different between the groups $(p=0.181)$. Within-group analyses showed that bladder base displacement was large in both groups after the respective intervention. There were no significant differences in any of the outcomes between the two groups before and after the intervention.

Conclusions: Vaginal palpation and transabdominal ultrasound might be useful for comprehending pelvic floor muscle contraction after vaginal delivery.

Trial registration: UMIN 000032304. Registered 18 April 2018, https://upload.umin.ac.jp/cgi-open-bin/icdr_e/ctr_view. cgi?recptno=R000036820.

\footnotetext{
*Correspondence: ikeda-m@med.teikyo-u.ac.jp

${ }^{1}$ Graduate Course of Midwifery, Teikyo University, 2-11-1 Kaga,

Itabashi-ku, Tokyo, Japan

Full list of author information is available at the end of the article
}

(c) The Author(s) 2021. Open Access This article is licensed under a Creative Commons Attribution 4.0 International License, which permits use, sharing, adaptation, distribution and reproduction in any medium or format, as long as you give appropriate credit to the original author(s) and the source, provide a link to the Creative Commons licence, and indicate if changes were made. The images or other third party material in this article are included in the article's Creative Commons licence, unless indicated otherwise in a credit line to the material. If material is not included in the article's Creative Commons licence and your intended use is not permitted by statutory regulation or exceeds the permitted use, you will need to obtain permission directly from the copyright holder. To view a copy of this licence, visit http://creativecommons.org/licenses/by/4.0/. The Creative Commons Public Domain Dedication waiver (http://creativeco mmons.org/publicdomain/zero/1.0/) applies to the data made available in this article, unless otherwise stated in a credit line to the data. 
Keywords: Pelvic floor muscle contraction, Vaginal palpation, Transabdominal ultrasound, Vaginal delivery, Randomised controlled trial, Bladder base, Postpartum, Urinary incontinence, Perineal injury

\section{Background}

Vaginal delivery carries the highest risk for lower urinary tract symptoms; the incidence of such symptoms is 6.1 times higher in women who underwent vaginal delivery than in those who underwent caesarean section [1]. Pelvic floor weakness and urinary incontinence are important issues in women's health. Vaginal delivery is an independent risk factor for damage to the pelvic floor muscles (PFMs) [2], and pelvic floor distensibility may cause pelvic floor dysfunction, such as urinary incontinence and pelvic organ prolapse, later in life irrespective of the delivery mode [3]. PFM training is commonly recommended during pregnancy and postpartum period for the prevention and treatment of incontinence [4]. Recent studies have shown that PFM training is effective for the treatment of genitourinary syndrome of menopause as well as reducing its symptoms and signs and its effects on activities of daily living, quality of life, and sexual function [5]. It has been suggested that PFM training improves blood flow and elasticity of the vulvovaginal tissue [6]. Therefore, education on how to correctly contract PFMs and increase their strength, during and after pregnancy, may also contribute to postmenopausal women's health. As many women are not aware of the preventive measures and treatment options, it would be beneficial to raise such awareness and provide the required care by midwives [7].

In Japan, education on PFM training after delivery commonly includes only oral teaching by midwives using leaflets. However, since PFM contraction cannot be visualised, it is difficult for women to comprehend how to contract and relax based on oral teaching alone. Furthermore, women do not generally know how to perform PFM contraction and therefore are unsure if they are performing contractions correctly during PFM training [8]. Therefore, it is necessary to establish a teaching method that enables such learning.

Vaginal palpation (VP) has been shown to be important in teaching how to perform PFM contraction correctly [9]. It has been reported to be a superior method compared to sonography for measuring indices of contractile function [10] and the gold standard to assess PFM contraction ability [11].

Recently, ultrasound was introduced in clinical practice as a new method to assess correct PFM contraction [12]. Both transperineal and transabdominal ultrasound (TAU) were shown to be reliable in measuring movement during PFM contraction [13]. Especially, TAU is non-invasive, allows visualisation, provides immediate visual feedback, and is easy to apply [14]. TAU imaging is used to assess PFM contraction by observing the movement of the bladder base as a surrogate marker for PFM activity. Bladder base displacement because of voluntary PFM contraction has been corroborated by previous findings [15].

Postpartum women are expected to have reduced pelvic floor function; therefore, we predicted that VP, as a direct tactile evaluation, would an easier method in understanding PFM contraction than TAU. The aim of this study was to assess the changes in comprehension of PFM contraction by comparing the two teaching methods, VP and TAU, following vaginal delivery. We hypothesised that VP is better suited than TAU for understanding PFM contraction.

\section{Methods}

\section{Study design and participants}

This two-arm randomised controlled trial was conducted in three facilities in Tokyo, Japan, in women who gave birth in primary facilities, such as midwifery home and gynaecology clinic. Data were collected between July 2018 and January 2019. The eligibility criteria were as follows: (1) age $\geqq 20$ years; (2) vaginal delivery; and (3) 4-6 weeks after term delivery. Women were excluded from the study if (1) they had previously received guidance for PFM contraction via VP or TAU; (2) they deviated from a normal status of obstetrics and urology; (3) they had perineal pain or numbness at the time of intervention; (4) they had urinary nerve damage; and (5) they were not able to read and write in Japanese.

This trial was registered with the UMIN Clinical Trials Registry (registration no. UMIN000032304).

\section{Randomisation}

The participants were assigned to either the VP or TAU group. The randomisation involved centralised allocation managed by a web-based randomisation system with permuted blocks of four. Due to the nature of the intervention, masking of the intervener and participants was not possible, and the data were not masked by assignment during the analysis.

\section{Procedures}

The intervention was performed by the intervener (midwife) alone, who implemented either the technique of VP by touching the PFMs in the VP group or TAU by 
showing an extracted image in the TAU group. The details of each teaching protocol are as follows.

VP group: The intervener slowly inserted two fingers of the right hand into the participant's vagina and instructed the participant to lift and squeeze around the fingers. The intervener then provided feedback to the participant regarding the contraction on VP. Using the left hand, the intervener held two fingers of the participant's right hand similar to those inserted into the vagina for palpation. The intervener alternately squeezed and relaxed the participant's right hand in conjunction with the intravaginal contraction in order to provide tactile feedback to the patient.

TAU group: The intervener placed the ultrasound probe in the sagittal plane just above the pubic bone and instructed the participant to lift and squeeze the pelvic floor toward the head, while showing the extracted bladder base images on the ultrasound screen. The intervener taught the participants how to contract the PFMs by showing them the TAU images. The intervener provided feedback to the participants about the contractions using ultrasound images of the elevation of the bladder base during PFM contraction and the descent of the bladder base during relaxation.

To ensure uniformity and objectivity of each intervention, the teaching instructions were integrated according to specific protocols. However, the instructions that were similar in both groups were as follows:

1. The intervention was performed in a private room and at least $1 \mathrm{~h}$ after urination. The participants lay in a crook-lying position (supine position with hips and knees flexed) [16] with their soles flat on the same level of the bed and a pillow underneath their head.

2. The method of PFM contraction was explained while explaining the anatomy of PFMs using a diagram.

3. The participants practiced 10 fast and 10 endurance contractions without contracting the abdominal muscles while maintaining normal breathing.

4. The participants practiced for $10 \mathrm{~min}$.

\section{Study outcomes}

Changes in the pre- and post-intervention comprehension of PFM contraction were assessed by changes in the displacement of the bladder base during contraction and changes in understanding the contraction. Changes in bladder base displacement were measured using TAU pre-intervention, and post-intervention changes were measured similarly after a 5-min break. The measurement was performed without showing the ultrasound screen to the participants to avoid any visual feedback effect. The TAU probe was placed in the mid-sagittal plane immediately supra-pubically on the lower abdomen [11]. The measurement point was a clearly defined edge of maximum displacement of the fascia between the interureteric ridges in the bladder base and bladder neck $[17,18]$, and the distance between PFM relaxation and contraction was measured in $\mathrm{mm}$ using an on-screen calliper. The participants performed three repetitions of maximum voluntary contractions for $3 \mathrm{~s}$ with $10 \mathrm{~s}$ of relaxation between each contraction, and the mean value was used in the statistical analysis [19]. TAU is valid and reliable in assessing PFM function, and different bladder volumes do not influence the displacement measures; therefore, a strict bladder filling protocol was not necessary [20]. TAU was performed using LOGIQeV2 (GE Healthcare Japan Corp, Tokyo, Japan) with a 3.5-5.5$\mathrm{MHz}$ curved array transducer. A representative image of the displacement of the bladder base during PFM contraction is shown in Fig. 1.

Pre- and post-intervention changes in understanding PFM contractions were assessed using a two-item questionnaire, which included the questions 'Do you know where to contract in the body?' and 'Do you understand the sensation of contracting the pelvic floor muscles?', as previously reported [21]. The questionnaire used a fivepoint Likert scale (1-5 points), and a higher score indicated better understanding.

Prior to the intervention, urinary incontinence was assessed using the Japanese version of the International Consultation on Incontinence Questionnaire-Short Form (ICIQ-SF), which was created through the process of linguistic validity verification, and its reliability and validity have been previously verified [22]. We have obtained permission to use the Japanese version of ICIQ-SF. We also collected information on the frequency of PFM training and demographic information about the participants.

\section{Statistical analyses}

Statistical analyses were performed using SPSS Statistics v24 for Windows (IBM Inc., Armonk, NY, USA). Comparisons of the demographic data, ICIQ-SF scores, and frequency of PFM training were performed using the chi-square test and t-test. Changes in the comprehension of PFM contraction between the groups were compared using the Welch's t-test.

\section{Sample size}

The sample size was calculated based on a previous randomised controlled study that verified the effects of PFM training in women with pelvic organ prolapse [23]. In that study, the intervention group received individual training by a physiotherapist for 6 months, and the control group received guidance as usual; the resting position of the bladder increased by a mean of $4.2 \mathrm{~mm}$ 


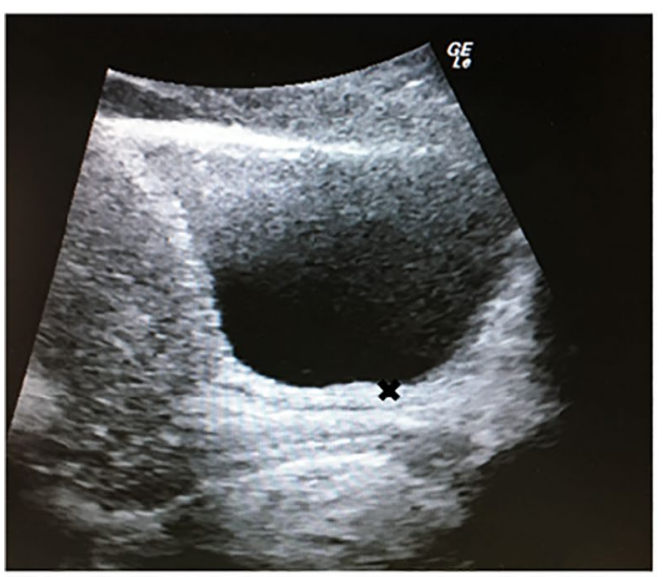

Pelvic floor muscle relaxation

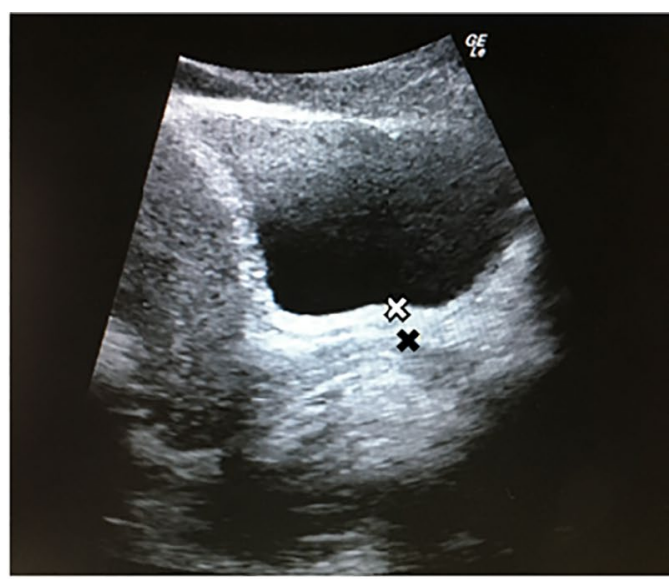

Contraction : Displaced from black to white

Fig. 1 Displacement of the bladder base during pelvic floor muscle contraction

[95\% confidence interval (CI), 2.8-5.6] in the intervention group and $-0.1 \mathrm{~mm}(\mathrm{CI},-1.9$ to 1.6$)$ in the control group. Therefore, for an effect size of 0.75 , power of $80 \%$, and significance level of 0.05 , the estimated sample size was 28 women in each group.

\section{Results}

\section{Participant inclusion}

For this study, 471 eligible postpartum women were identified between July 2018 and January 2019. When the sample size was reached, the recruitment was stopped. Four women were excluded before randomisation because they were not within the 4-6 weeks postpartum period, and 402 women refused the invitation to participate. Therefore, a total of 65 women participated in the study; 32 were allocated to the VP group and 33 to the TAU group. After random assignment, there was no dropout until the end of the study, and all of the 65 participants were included in the outcome analysis (Fig. 2).

\section{Baseline characteristics}

Baseline data comparison revealed no differences between the two groups in all items, including the demographic data, frequency of PFM training, status of urinary incontinence, and ICIQ-SF score (Table 1).

\section{Outcome measures main analysis}

The mean \pm standard deviation (SD) bladder base displacement before the intervention was $5.80 \pm 4.69 \mathrm{~mm}$ in the VP group and $6.04 \pm 5.05 \mathrm{~mm}$ in the TAU group, which were not significantly different. After the intervention, the bladder base displacement was $6.91 \pm 3.31 \mathrm{~mm}$ in the VP group and $6.19 \pm 4.05$ in the TAU group. The change in bladder base displacement was greater in the VP group $(1.11 \pm 2.34 \mathrm{~mm})$ than in the TAU group $(0.15 \pm 3.28 \mathrm{~mm})$; however, the difference was not statistically significant (Table 2).

In the two-item questionnaire to assess the understanding of PFM contraction, the question 'Do you know where to contract in the body?' was answered as 'Hard to understand' by nine participants and 'Did not understand' by one participant in the VP group before the intervention. The question 'Do you understand the sensation of contracting the pelvic floor muscles?' was answered with 'Hard to understand' by eight participants and 'Did not understand' by two participants, in the VP group before the intervention. After the intervention, both items of the questionnaire were answered by all 32 participants in the VP group as either 'Extremely well' or 'Moderately well'. In contrast, the first question was answered with 'Hard to understand' and 'Did not understand' by five and two participants in the TAU group, respectively, before the intervention. The second question was answered with 'Hard to understand' by eight participants in this group. After the intervention, in the TAU group, two participants answered the first question with 'Hard to understand,' one of whom also answered the second question with 'Hard to understand. Nevertheless, there was no statistically significant difference between the two groups regarding the changes in the understanding of PFM contraction after implementation of the two teaching methods (Table 3).

\section{Ancillary analysis}

Participants with perineal injuries or urinary incontinence were sub-grouped and analysed to determine the differences in the results according to the teaching method. 


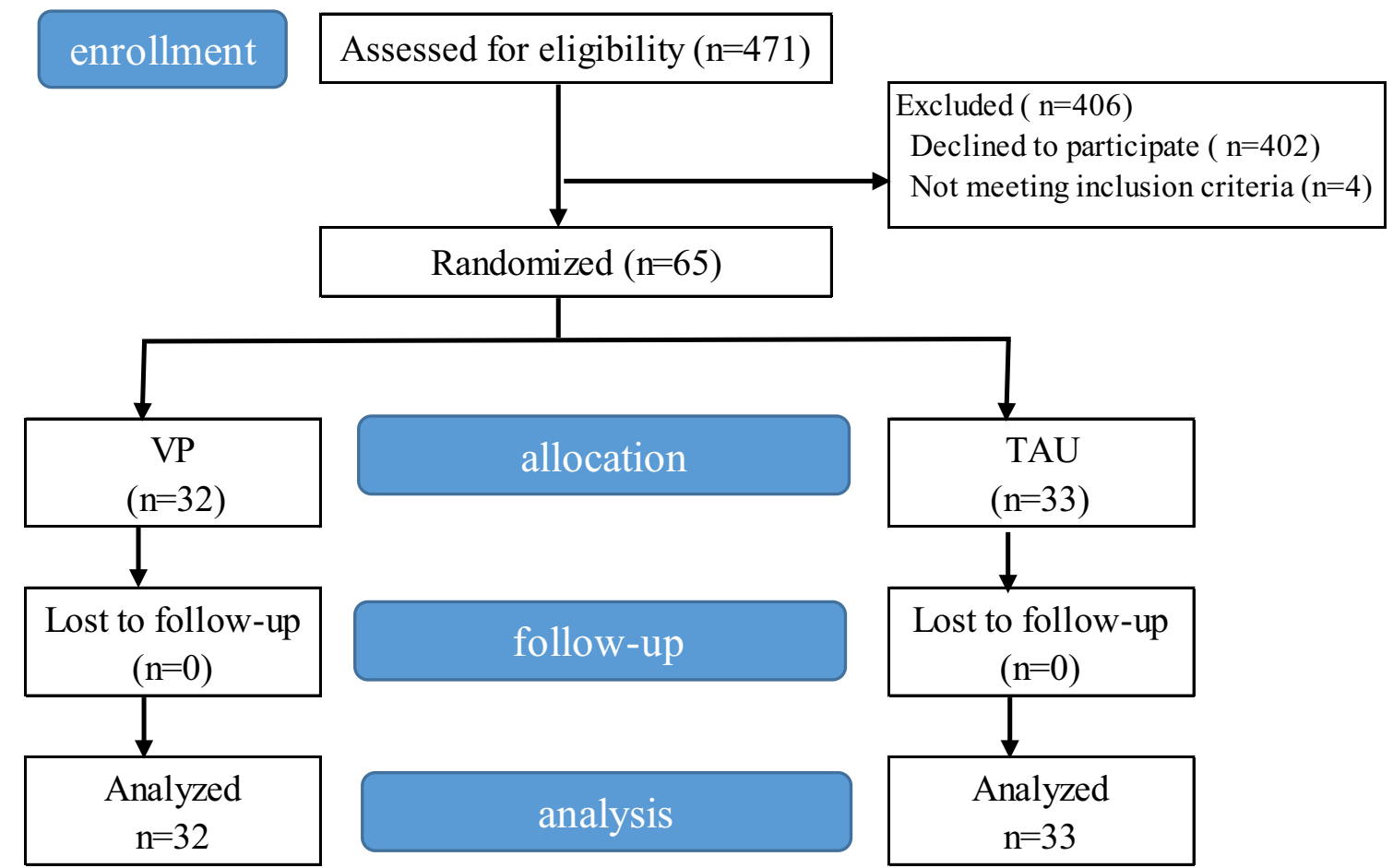

Fig. 2 Inclusion of the participants in the study. VP vaginal palpation, TAU transabdominal ultrasound

Participants in the VP and TAU groups were subdivided into two sub-groups according to the presence or absence of perineal injuries (episiotomy or laceration)the perineal injury group and perineal intact group (Table 4). Seventeen participants in the VP group and 18 in the TAU group had perineal injuries. Women who had perineal injuries (episiotomy or laceration) received sutures for the same. Pre-test bladder base displacement was similar between the groups. Before and after the intervention, bladder floor displacement was larger in the perineal intact group than in the perineal injury group. Specifically, the change in bladder floor displacement after the intervention in participants in the VP group with perineal injuries was $1.55 \pm 2.71 \mathrm{~mm}$, while that in participants in the TAU group with injuries was $-0.10 \pm 4.08 \mathrm{~mm}$, which were not statistically significantly different. Furthermore, the change in women without injuries (perineal intact group) was $0.61 \pm 1.80 \mathrm{~mm}$ in the VP group and $0.46 \pm 2.02 \mathrm{~mm}$ in the TAU group, with no statistically significant differences between the two groups.

Similarly, participants in the VP and TAU groups were subdivided into the incontinent and continent group depending on the presence or absence of urinary incontinence, respectively (Table 5). Thirteen participants (40.6\%) in the VP group and 14 (42.4\%) in the TAU group had urinary incontinence. Bladder base displacement before the intervention was comparable between the groups. Unexpectedly, both before and after the intervention, the bladder base displacement was larger in the incontinent group than in the continent group. Specifically, the change in bladder floor displacement after the intervention in participants in the incontinent group was $0.75 \pm 2.09 \mathrm{~mm}$ in the VP group and $-0.95 \pm 2.93 \mathrm{~mm}$ in the TAU group with no statistically significant differences between the two groups. Furthermore, the change in bladder floor displacement after the intervention in participants in the continent group was $1.35 \pm 2.52 \mathrm{~mm}$ and $0.96 \pm 3.35 \mathrm{~mm}$ in the VP and TAU groups, respectively, although no statistically significant differences were observed between the two groups.

\section{Adverse events}

No adverse events associated with the two interventions were reported by the participants.

\section{Discussion}

This study examined the changes in comprehension of PFM contraction by comparing two teaching methods, VP and TAU, in women after vaginal delivery. Contrary to our hypothesis that VP would be more suitable than TAU in improving the understanding of PFM contraction, we found no significant differences between the two teaching methods. 
Table 1 Baseline characteristics of participants

\begin{tabular}{|c|c|c|c|}
\hline Characteristics & & VP $n=32$ & TAU $n=33$ \\
\hline Postpartum days & M (SD) & $36.8(5.4)$ & $37.2(5.4)$ \\
\hline Age (years) & $M(S D)$ & $34.9(3.8)$ & $33.2(4.1)$ \\
\hline $\begin{array}{l}\text { Body mass index before preg- } \\
\text { nancy }\end{array}$ & $\mathrm{M}(\mathrm{SD})$ & $21.0(2.8)$ & $20.9(2.4)$ \\
\hline Duration of labor (min) & $M(S D)$ & $420.6(247.1)$ & $353.9(261.8)$ \\
\hline Birth weight (grams) & $M(S D)$ & $3142.5(293.8)$ & $3028.3(326.0)$ \\
\hline \multicolumn{4}{|l|}{ Parity } \\
\hline Primipara & n (\%) & $7(21.9)$ & $9(27.3)$ \\
\hline Multipara & n (\%) & $25(78.1)$ & $24(72.7)$ \\
\hline \multicolumn{4}{|l|}{ Type of delivery } \\
\hline Normal & n (\%) & $28(87.6)$ & $30(90.9)$ \\
\hline Vacuum extraction & n (\%) & $2(6.3)$ & $1(3.0)$ \\
\hline Epidural birth & n (\%) & $2(6.3)$ & $2(6.1)$ \\
\hline \multicolumn{4}{|l|}{ Perineal condition } \\
\hline Episiotomy & n (\%) & $1(3.1)$ & $4(12.1)$ \\
\hline Laceration, first degree & n (\%) & $10(31.2)$ & $6(18.2)$ \\
\hline Laceration, second degree & n (\%) & $4(12.5)$ & $8(24.2)$ \\
\hline Episiotomy and laceration & n (\%) & $2(6.3)$ & $0(0.0)$ \\
\hline Intact & n (\%) & $15(46.9)$ & $15(45.5)$ \\
\hline \multicolumn{4}{|l|}{ Frequency of PFMT } \\
\hline Did not perform & n (\%) & $21(65.6)$ & $19(57.6)$ \\
\hline Performed sometimes & n (\%) & $9(28.1)$ & $14(42.4)$ \\
\hline Performed daily & n (\%) & $2(6.3)$ & $0(0.0)$ \\
\hline \multicolumn{4}{|l|}{ Daily number of PFMT performed } \\
\hline $0-9$ & n (\%) & $27(84.4)$ & $27(81.8)$ \\
\hline $10-29$ & n (\%) & $5(15.6)$ & $5(15.2)$ \\
\hline More than 30 & n (\%) & $0(0.0)$ & $1(3.0)$ \\
\hline \multicolumn{4}{|l|}{ Urinary incontinence } \\
\hline Continent & n (\%) & $19(59.4)$ & $19(57.6)$ \\
\hline Incontinent & n (\%) & $13(40.6)$ & $14(42.4)$ \\
\hline ICIQ-SF score & $M(S D)$ & $2.81(3.85)$ & $2.91(3.99)$ \\
\hline
\end{tabular}

$V P$ vaginal palpation, TAU transabdominal ultrasound, $S D$ standard deviation, PFMT pelvic floor muscle training, ICIQ-SF International Consultation on Incontinence Questionnaire-Short Form

The main difference between the two interventions is that VP has a more direct effect than TAU, which is device-based. Although the changes in PFM contraction after the intervention were greater in the VP group than in the TAU group, no statistically significant differences were observed between the two groups. The lack of such differences could be explained by the fact that the feedback received by the participants involved physical sensations (tactile and visual) in both interventions. Providing feedback to the participant during the intervention was shown to be effective in PFM training [24]. Our findings suggested that both tactile and visual feedback may be useful and easy to understand. Another reason for the non-significant differences may be the small sample size. The previous study on which we based our sample size calculations included a Western population with different body characteristics from those in Japanese women. Nevertheless, given the small sample size of our study, such a hypothesis may need to be tested in larger samples.

Sub-group analyses also indicated that in participants with perineal injuries or urinary incontinence, changes in bladder base displacement after the intervention were greater with VP than with TAU, although the differences were not statistically significant. Furthermore, the displacement of the bladder base was larger in the incontinent group than in the continent group. This result corresponds well with those of previous studies in which the inability to correctly perform PFM contraction was not associated with urinary incontinence [25].

VP has the advantage that it does not require expensive tools and can be performed at any time desired by the participant. The disadvantage is that it is invasive and participants may feel uncomfortable. In contrast, TAU is totally non-invasive, and the patient does not need to get undressed. The advantages of TAU may be used in populations where VP may not be appropriate, such as in women with vaginal pain or who feel uncomfortable [14]. Our results verified that TAU is as useful as VP as a teaching method in postpartum women. However, TAU requires a full bladder, which may be difficult in women with reduced bladder function capacity or bladder urgency, and it may be difficult to obtain a clear image in women with dense abdominal scar tissue [13]. An additional disadvantage of using TAU alone in postpartum women is that it does not allow easy observation of the

Table 2 Changes in bladder base displacement

\begin{tabular}{|c|c|c|c|c|c|c|}
\hline & \multicolumn{2}{|c|}{$\mathrm{VP}(\mathrm{n}=32)$} & \multicolumn{2}{|c|}{$\operatorname{TAU}(n=33)$} & \multirow[t]{2}{*}{$t$-value } & \multirow[t]{2}{*}{$p$-value } \\
\hline & Mean & SD & Mean & SD & & \\
\hline \multicolumn{7}{|c|}{ Displacement (mm) } \\
\hline Pre & 5.80 & 4.69 & 6.04 & 5.05 & & \\
\hline Post & 6.91 & 3.31 & 6.19 & 4.05 & & \\
\hline Change & 1.11 & 2.34 & 0.15 & 3.28 & 1.355 & 0.181 \\
\hline
\end{tabular}

VP vaginal palpation, TAU transabdominal ultrasound, SD standard deviation 
Table 3 Change in understanding PFM contraction

\begin{tabular}{|c|c|c|c|c|c|c|}
\hline & \multicolumn{2}{|c|}{$\operatorname{VP}(n=32)$} & \multicolumn{2}{|c|}{$\operatorname{TAU}(n=33)$} & \multirow[t]{2}{*}{$t$-value } & \multirow[t]{2}{*}{$p$-value } \\
\hline & Mean & SD & Mean & SD & & \\
\hline \multicolumn{7}{|c|}{ Understanding of PFMC (score) } \\
\hline Pre & 6.59 & 2.09 & 7.12 & 1.83 & & \\
\hline Post & 9.43 & 0.88 & 9.09 & 1.26 & & \\
\hline Change & 2.84 & 1.97 & 1.97 & 1.63 & 1.946 & 0.056 \\
\hline
\end{tabular}

PFM pelvic floor muscle, PFMC pelvic floor muscle contraction, VP vaginal palpation, TAU transabdominal ultrasound, SD standard deviation

Table 4 Changes in displacement of the bladder base according to the perineal condition

\begin{tabular}{|c|c|c|c|c|c|c|c|c|c|c|c|c|}
\hline & \multicolumn{4}{|c|}{ Perineal injury $(n=35)$} & \multirow[t]{3}{*}{$t$ value } & \multirow[t]{3}{*}{$p$ value } & \multicolumn{4}{|c|}{ Perineal intact $(n=30)$} & \multirow[t]{3}{*}{$t$ value } & \multirow[t]{3}{*}{$p$ value } \\
\hline & \multicolumn{2}{|c|}{$\operatorname{VP}(n=17)$} & \multicolumn{2}{|c|}{$\operatorname{TAU}(n=18)$} & & & \multicolumn{2}{|c|}{$\operatorname{VP}(n=15)$} & \multicolumn{2}{|c|}{$\operatorname{TAU}(n=15)$} & & \\
\hline & Mean & SD & Mean & SD & & & Mean & SD & Mean & SD & & \\
\hline \multicolumn{13}{|c|}{ Displacement (mm) } \\
\hline Pre & 4.83 & 4.23 & 4.91 & 5.15 & & & 6.90 & 5.07 & 7.40 & 4.75 & & \\
\hline Post & 6.38 & 2.69 & 4.81 & 3.93 & & & 7.51 & 3.91 & 7.86 & 3.66 & & \\
\hline Change & 1.55 & 2.71 & -0.10 & 4.08 & -1.171 & 0.252 & 0.61 & 1.80 & 0.46 & 2.02 & 0.507 & 0.616 \\
\hline
\end{tabular}

VP vaginal palpation, TAU transabdominal ultrasound, SD standard deviation

Table 5 Changes in displacement of the bladder base according to urinary incontinence

\begin{tabular}{|c|c|c|c|c|c|c|c|c|c|c|c|c|}
\hline & \multicolumn{4}{|c|}{ Incontinent $(n=27)$} & \multirow[t]{3}{*}{$t$ value } & \multirow[t]{3}{*}{$p$ value } & \multicolumn{4}{|c|}{ Continent $(n=38)$} & \multirow[t]{3}{*}{$t$ value } & \multirow[t]{3}{*}{$p$ value } \\
\hline & \multicolumn{2}{|c|}{$\operatorname{VP}(n=13)$} & \multicolumn{2}{|c|}{$\operatorname{TAU}(n=14)$} & & & \multicolumn{2}{|c|}{$\operatorname{VP}(n=19)$} & \multicolumn{2}{|c|}{$\operatorname{TAU}(n=19)$} & & \\
\hline & Mean & SD & Mean & SD & & & Mean & SD & Mean & SD & & \\
\hline \multicolumn{13}{|c|}{ Displacement (mm) } \\
\hline Pre & 6.47 & 5.57 & 8.05 & 5.87 & & & 5.34 & 4.07 & 4.57 & 3.88 & & \\
\hline Post & 7.22 & 4.07 & 7.10 & 3.82 & & & 6.69 & 2.78 & 5.53 & 4.19 & & \\
\hline Change & 0.75 & 2.09 & -0.95 & 2.93 & 1.747 & 0.094 & 1.35 & 2.52 & 0.96 & 3.35 & 0.400 & 0.692 \\
\hline
\end{tabular}

VP vaginal palpation, TAU transabdominal ultrasound, SD standard deviation

vulva. Therefore, the vulva should be monitored for perineal injuries.

Within the groups, bladder base displacement was larger after the intervention than before it. In order to increase the muscle strength, a previous study recommended the use of a training protocol that follows strength-training principles, emphasises close to maximum contractions, and lasts at least 8 weeks [26]. Therefore, the observed improvement in our study may not be attributed to increased PFM strength after the intervention due to the short duration of the intervention but rather can be attributed to changes in the comprehension of PFM contraction through the intervention.

A previous systematic review reported that TAU measures bladder base displacement between 3.7 and $8.7 \mathrm{~mm}$ in the supine position [27]. A recent study measured bladder base displacement in the midsagittal plane using TAU and reported PFM displacement of $7.8 \pm 4.5 \mathrm{~mm}$ in the supine position in 17 young healthy nulliparous women [28]. In our study, the participants were low-risk women, predominantly multiparous, and at 4-6 weeks after delivery. The displacement of the bladder base during PFM contraction was not comparable to that in young healthy nulliparous women but was not significantly inferior. Although different results may be observed in participants with pelvic floor disorders, our results might be useful when targeting low-risk postpartum women.

\section{Limitations}

This study had a few limitations. First, it was not possible to mask the group allocation. Second, we did not investigate whether the intervention was being 
implemented continuously as we compared the changes in the participant's comprehension of PFM contraction with each teaching method. Future research is needed to evaluate the study outcomes after continuing PFM training for a longer duration. Finally, since the participants were low-risk postpartum women, it is necessary to also consider high-risk participants in the future.

\section{Conclusions}

In this study, we hypothesised that VP is better than TAU for improving comprehension of PFM contraction as assessed by bladder base displacement during PFM contraction and the changes in the understanding of PFM contraction after the intervention. However, we found no significant differences between these methods, thus suggesting that both teaching methods might be useful for the comprehension of PFM contraction after vaginal delivery. In clinical practice, individual preferences must be considered, and a personalised teaching method should be chosen according to the various advantages and disadvantages of VP and TAU.

\section{Abbreviations}

$\mathrm{Cl}$ : Confidence interval; ICIQ-SF: International Consultation on Incontinence Questionnaire-Short Form; PFM: Pelvic floor muscle; SD: Standard deviation; TAU: Transabdominal ultrasound; VP: Vaginal palpation.

\section{Acknowledgements}

The authors thank the participants and the staff who helped in this study. The authors also appreciate the support and precious advice by Dr. Yaeko Kataoka and Dr. Yukari Yaju of St. Luke's International University, Japan; and Dr. Tamami Taniguchi of Yamanashi University, Japan.

\section{Authors' contributions}

MI participated in the conception and design of the study, acquisition of data, analysis, and drafting the manuscript. AM substantially contributed to the design of the study, interpretation of data, and completion of the manuscript. Both authors have read and approved the final manuscript.

\section{Funding}

This study was supported by a grant-in-aid of the Japan Health Academy, 2018. The Japan Health Academy had no role in the design of the study and collection, analysis, and interpretation of data and in writing the manuscript.

\section{Availability of data and materials}

The datasets generated during and/or analysed during the current study are available from the corresponding author on reasonable request.

\section{Ethics approval and consent to participate}

This study was approved by the Research Ethics Review Committee of St. Luke's International university, Tokyo, Japan (No. 18-A005). All participants provided written informed consent prior to participating in the study.

\section{Consent for publication}

Not applicable.

\section{Competing interests}

The authors declare that they have no competing interests.

\section{Author details}

${ }^{1}$ Graduate Course of Midwifery, Teikyo University, 2-11-1 Kaga, Itabashi-ku, Tokyo, Japan. ${ }^{2}$ Department of Nursing, Shonan Kamakura University of Medical Sciences School of Nursing, 1195-3 Yamazaki, Kamakura-shi, Kanagawa, Japan.

Received: 20 May 2020 Accepted: 1 February 2021

Published online: 06 February 2021

References

1. Timur-Taşhan S, Beji NK, Aslan E, Yalçin Ö. Determining lower urinary tract symptoms and associated risk factors in young women. Int J Gynaecol Obstet. 2012;118:27-30

2. Zhao Y, Zou L, Xiao M, Tang W, Niu HY, Qiao FY. Effect of different delivery modes on the short-term strength of the pelvic floor muscle in Chinese primipara. BMC Pregnancy Childbirth. 2018;18:275.

3. van Veelen GA, Schweitzer KJ, van der Vaart $\mathrm{CH}$. Ultrasound imaging of the pelvic floor: changes in anatomy during and after first pregnancy. Ultrasound Obstet Gynecol. 2014;44:476-80.

4. Woodley SJ, Boyle R, Cody JD, Mørkved S, Hay-Smith EJC. Pelvic floor muscle training for prevention and treatment of urinary and faecal incontinence in antenatal and postnatal women. Cochrane Database Syst Rev. 2017;12:CD007471.

5. Mercier J, Morin M, Zaki D, Reichetzer B, Lemieux MC, Khalifé S, et al. Pelvic floor muscle training as a treatment for genitourinary syndrome of menopause: a single-arm feasibility study. Maturitas. 2019;125:57-62.

6. Mercier J, Morin M, Tang A, Reichetzer B, Lemieux MC, Samir K, et al. Pelvic floor muscle training: mechanisms of action for the improvement of genitourinary syndrome of menopause. Climacteric. 2020;23:468-73.

7. Perera J, Kirthinanda DS, Wijeratne S, Wickramarachchi TK. Descriptive cross sectional study on prevalence, perceptions, predisposing factors and health seeking behaviour of women with stress urinary incontinence. BMC Womens Health. 2014;14:78.

8. Grant A, Currie S. Qualitative exploration of the acceptability of a postnatal pelvic floor muscle training intervention to prevent urinary incontinence. BMC Womens Health. 2020;20:9.

9. $B \varnothing \mathrm{K}$, Finckenhagen HB. Vaginal palpation of pelvic floor muscle strength: inter-test reproducibility and comparison between palpation and vaginal squeeze pressure. Acta Obstet Gynecol Scand. 2001;80:883-7.

10. Guzmán Rojas R, Wong V, Shek KL, Dietz HP. Impact of levator trauma on pelvic floor muscle function. Int Urogynecol J. 2014;25:375-80.

11. Bø K, Sherburn M. Evaluation of female pelvic-floor muscle function and strength. Phys Ther. 2005;85:269-82.

12. Thompson JA, O'Sullivan PB, Briffa NK, Neumann P. Comparison of transperineal and transabdominal ultrasound in the assessment of voluntary pelvic floor muscle contractions and functional manoeuvres in continent and incontinent women. Int Urogynecol J Pelvic Floor Dysfunct. 2007:18:779-86.

13. Thompson JA, O'Sullivan PB, Briffa K, Neumann P, Court S. Assessment of pelvic floor movement using transabdominal and transperineal ultrasound. Int Urogynecol J Pelvic Floor Dysfunct. 2005;16:285-92.

14. Thompson JA, O'Sullivan PB. Levator plate movement during voluntary pelvic floor muscle contraction in subjects with incontinence and prolapse: a cross-sectional study and review. Int Urogynecol J Pelvic Floor Dysfunct. 2003;14:84-8.

15. Frawley HC, Galea MP, Phillips BA, Sherburn M, Bø K. Effect of test position on pelvic floor muscle assessment. Int Urogynecol J Pelvic Floor Dysfunct. 2006;17:365-71.

16. Whittaker JL, Thompson JA, Teyhen DS, Hodges P. Rehabilitative ultrasound imaging of pelvic floor muscle function. J Orthop Sports Phys Ther. 2007;37:487-98.

17. Bø K, Sherburn M, Allen T. Transabdominal ultrasound measurement of pelvic floor muscle activity when activated directly or via a transversus abdominis muscle contraction. Neurourol Urodyn. 2003;22:582-8.

18. Okamoto M, Murayama R, Haruna M, Matsuzaki M, Kozuma S, Nakata M, Murashima S. Evaluation of pelvic floor function by transabdominal ultrasound in postpartum women. J Med Ultrason. 2001;2010(37):187-93.

19. Chehrehrazi M, Arab AM, Karimi N, Zargham M. Assessment of pelvic floor muscle contraction in stress urinary incontinent women: comparison 
between transabdominal ultrasound and perineometry. Int Urogynecol J Pelvic Floor Dysfunct. 2009;20:1491-6.

20. Sherburn M, Murphy CA, Carroll S, Allen TJ, Galea MP. Investigation of transabdominal real-time ultrasound to visualise the muscles of the pelvic floor. Aust J Physiother. 2005;51:167-70.

21. Ikeda M. The utility of teaching women pelvic floor muscle training with vaginal palpation: Evaluation by postpartum women. J Jpn Acad Midwif. 2019;33:185-99 ((Published in Japanese)).

22. Gotoh M, Homma Y, Funahashi Y, Matsukawa Y, Kato M. Psychometric validation of the Japanese version of the International Consultation on Incontinence Questionnaire-Short Form. Int J Urol. 2009;16:303-6.

23. Braekken $I H$, Majida M, Engh ME, Bø K. Morphological changes after pelvic floor muscle training measured by 3-dimensional ultrasonography: a randomized controlled trial. Obstet Gynecol. 2010;115:317-24.

24. Herderschee R, Hay-Smith EC, Herbison GP, Roovers JP, Heineman MJ. Feedback or biofeedback to augment pelvic floor muscle training for urinary incontinence in women: shortened version of a Cochrane systematic review. Neurourol Urodyn. 2013;32:325-9.
25. Barton A, Serrao C, Thompson J, Briffa K. Transabdominal ultrasound to assess pelvic floor muscle performance during abdominal curl in exercising women. Int Urogynecol J. 2015;26:1789-95.

26. Mørkved $\mathrm{S}, \mathrm{B} \varnothing \mathrm{K}$. Effect of pelvic floor muscle training during pregnancy and after childbirth on prevention and treatment of urinary incontinence: a systematic review. Br J Sports Med. 2014;48:299-310.

27. Leitner M, Moser H, Taeymans J, Kuhn A, Radlinger L. Pelvic floor muscle displacement during voluntary and involuntary activation in continent and incontinent women: a systematic review. Int Urogynecol J. 2015;26:1587-98.

28. Moser H, Luginbuehl H, Baeyens JP, Radlinger L. Reliability and validity of pelvic floor muscle displacement measurements during voluntary contractions. Int Urogynecol J. 2019;30:2093-100.

\section{Publisher's Note}

Springer Nature remains neutral with regard to jurisdictional claims in published maps and institutional affiliations.
Ready to submit your research? Choose BMC and benefit from:

- fast, convenient online submission

- thorough peer review by experienced researchers in your field

- rapid publication on acceptance

- support for research data, including large and complex data types

- gold Open Access which fosters wider collaboration and increased citations

- maximum visibility for your research: over $100 \mathrm{M}$ website views per year

At BMC, research is always in progress.

Learn more biomedcentral.com/submissions 